\title{
The modification of system of variational inequalities for fixed point theory in Banach spaces
}

Atid Kangtunyakarn*

\section{"Correspondence:}

beawrock@hotmail.com Department of Mathematics, Faculty of Science, King Mongkut's Institute of Technology Ladkrabang, Bangkok 10520, Thailand

\begin{abstract}
In this paper, we use methods different from extragradient methods to prove a strong convergence theorem for the sets of fixed points of two finite families of nonexpansive and strictly pseudo-contractive mappings and the set of solutions of modification of a system of variational inequalities problems in a uniformly convex and 2-uniformly smooth Banach space. Applying the main result we obtain a strong convergence theorem involving two sets of solutions of variational inequalities problems introduced by Aoyama et al. (Fixed Point Theory Appl. 2006:35390, 2006, doi:10.1155/FPTA/2006/35390) in a uniformly convex and 2-uniformly smooth Banach space. We also give a numerical example to support our result.
\end{abstract}

Keywords: nonexpansive mapping; strictly pseudo-contractive mapping; the modification of system of variational inequalities problems

\section{Introduction}

Let $E$ be a real Banach space with its dual space $E^{*}$ and let $C$ be a nonempty closed convex subset of $E$. Throughout this paper, we denote the norm of $E$ and $E^{*}$ by the same symbol $\|\cdot\|$. We use the symbols ' $\rightarrow$ ' and ' $\rightarrow$ ' to denote strong and weak convergence, respectively. Recall the following definitions.

Definition 1.1 A Banach space $E$ is said to be uniformly convex iff for any $\epsilon, 0<\epsilon \leq 2$, the inequalities $\|x\| \leq 1,\|y\| \leq 1$ and $\|x-y\| \geq \epsilon$ imply there exists a $\delta>0$ such that $\left\|\frac{x+y}{2}\right\| \leq$ $1-\delta$.

Definition 1.2 Let $E$ be a Banach space. Then a function $\rho_{E}: \mathbb{R}^{+} \rightarrow \mathbb{R}^{+}$is said to be the modulus of smoothness of $E$ if

$$
\rho_{E}(t)=\sup \left\{\frac{\|x+y\|+\|x-y\|}{2}-1:\|x\|=1,\|y\|=t\right\} .
$$

A Banach space $E$ is said to be uniformly smooth if

$$
\lim _{t \rightarrow 0} \frac{\rho_{E}(t)}{t}=0 .
$$

O2014 Kangtunyakarn; licensee Springer. This is an Open Access article distributed under the terms of the Creative Commons Attribution License (http://creativecommons.org/licenses/by/2.0), which permits unrestricted use, distribution, and reproduction in any medium, provided the original work is properly cited. 
Let $q>1$. A Banach space $E$ is said to be $q$-uniformly smooth if there exists a fixed constant $c>0$ such that $\rho_{E}(t) \leq c t^{q}$. It is easy to see that, if $E$ is $q$-uniformly smooth, then $q \leq 2$ and $E$ is uniformly smooth. Hilbert space, $L_{P}$ (or $l_{p}$ ) spaces, $0<p<\infty$ and the Sobolev spaces, $W_{m}^{p}, 0<p<\infty$ are $q$-uniformly smooth. Hilbert spaces are 2 -uniformly smooth, while

$$
L_{p}\left(\text { or } l_{p}\right) \text { or } W_{m}^{p} \text { is } \begin{cases}p \text {-uniformly smooth } & \text { if } 1<p<\infty \\ 2 \text {-uniformly smooth } & \text { if } p \geq 2 .\end{cases}
$$

Definition 1.3 A mapping $J$ from $E$ onto $E^{*}$ satisfying the condition

$$
J(x)=\left\{f \in E^{*}:\langle x, f\rangle=\|x\|^{2} \text { and }\|f\|=\|x\|\right\}
$$

is called the normalized duality mapping of $E$. The duality pair $\langle x, f\rangle$ represents $f(x)$ for $f \in E^{*}$ and $x \in E$.

It is well known that if $E$ is smooth, then $J$ is a single value, which we denote by $j$.

Definition 1.4 Let $C$ be a nonempty subset of a Banach space $E$ and $T: C \rightarrow C$ be a self-mapping. $T$ is called a nonexpansive mapping if

$$
\|T x-T y\| \leq\|x-y\|
$$

for all $x, y \in C$.

$T$ is called an $\eta$-strictly pseudo-contractive mapping if there exists a constant $\eta \in(0,1)$ such that

$$
\langle T x-T y, j(x-y)\rangle \leq\|x-y\|^{2}-\eta\|(I-T) x-(I-T) y\|^{2}
$$

for every $x, y \in C$ and for some $j(x-y) \in J(x-y)$. It is clear that (1.1) is equivalent to the following:

$$
\langle(I-T) x-(I-T) y, j(x-y)\rangle \geq \eta\|(I-T) x-(I-T) y\|^{2}
$$

for every $x, y \in C$ and for some $j(x-y) \in J(x-y)$.

Example 1.1 Let $\mathbb{R}$ be a real line endowed with Euclidean norm and let the mapping $T$ : $\left(0, \frac{1}{2}\right) \rightarrow\left(0, \frac{1}{2}\right)$ defined by

$$
T x:=\frac{x^{3}}{1+x^{2}}
$$

for all $x \in\left(0, \frac{1}{2}\right)$. Then $T$ is $\frac{3}{4}$-strictly pseudo-contractive mapping.

Example 1.2 Let $E$ be 2-uniformly smooth Banach space and let $T: E \rightarrow E$ be $\lambda$-strictly pseudo-contractive mapping. Let $K$ be the 2-uniformly smooth constant of $E$ and $0 \leq d \leq$ $\frac{\lambda}{K^{2}}$, then $(I-d(I-T))$ is a nonexpansive mapping. 
Definition 1.5 Let $C \subseteq E$ be closed convex and $Q_{C}$ be a mapping of $E$ onto $C$. The mapping $Q_{C}$ is said to be sunny if $Q_{C}\left(Q_{C} x+t\left(x-Q_{C} x\right)\right)=Q_{C} x$ for all $x \in E$ and $t \geq 0$. A mapping $Q_{C}$ is called retraction if $Q_{C}^{2}=Q_{C}$. A subset $C$ of $E$ is called a sunny nonexpansive retract of $E$ if there exists a sunny nonexpansive retraction of $E$ onto $C$.

An operator $A$ of $C$ into $E$ is said to be accretive if there exists $j(x-y) \in J(x-y)$ such that

$$
\langle A x-A y, j(x-y)\rangle \geq 0, \quad \forall x, y \in C .
$$

A mapping $A: C \rightarrow E$ is said to be $\alpha$-inverse strongly accretive if there exist $j(x-y) \in$ $J(x-y)$ and $\alpha>0$ such that

$$
\langle A x-A y, j(x-y)| \geq \alpha\|A x-A y\|^{2}, \quad \forall x, y \in C .
$$

Remark 1.1 From (1.2) and (1.3), if $T$ is an $\eta$-strictly pseudo-contractive mapping, then $I-T$ is an $\eta$-inverse strongly accretive.

In 2000, Ansari and Yao [1] introduced the system of generalized implicit variational inequalities and proved the existence of its solution. They derived the existence results for a solution of system of generalized variational inequalities and used their results as tools to establish the existence of a solution of system of optimization problems.

Ansari et al. [2] introduced the system of vector equilibrium problems and prove the existence of its solution. Moreover, they also applied their result to the system of vector variational inequalities. The results of [1] and [2] were used as tools to solve Nash problem for vector-value functions and (non)convex vector valued function.

Let $A, B: C \rightarrow E$ be two nonlinear mappings. In 2010 Yao et al. [3] introduced the system of general variational inequalities problem for finding $\left(x^{*}, y^{*}\right) \in C \times C$ such that

$$
\begin{cases}\left\langle A y^{*}+x^{*}-y^{*}, j\left(x-x^{*}\right)\right\rangle \geq 0, & \forall x \in C, \\ \left\langle B x^{*}+y^{*}-x^{*}, j\left(x-y^{*}\right)\right\rangle \geq 0, & \forall x \in C .\end{cases}
$$

They proved fixed points theorem by using modification of extragradient methods as follows.

Theorem 1.2 Let $C$ be a nonempty closed convex subset of a uniformly convex and 2-uniformly smooth Banach space $E$ which admits a weakly sequentially continuous duality mapping. Let $Q_{C}$ be the sunny nonexpansive retraction from $X$ into $C$. Let the mappings $A, B: C \rightarrow E$ be $\alpha$-inverse strongly accretive with $\alpha \geq K^{2}$ and $\beta$-inverse strongly accretive with $\beta \geq K^{2}$, respectively. Define the mapping by $G x=Q_{C}\left(Q_{C}(x-B x)-\lambda A Q_{C}(x-B x)\right)$ for all $x \in C$ and the set of fixed point of $G$ denoted by $\Omega \neq \emptyset$. For given $x_{0} \in C$, let the sequence $\left\{x_{n}\right\}$ be generated by

$$
\left\{\begin{array}{l}
y_{n}=Q_{C}\left(x_{n}-B x_{n}\right), \\
x_{n+1}=\alpha_{n} u+\beta_{n} x_{n}+\gamma_{n} Q_{C}\left(y_{n}-A y_{n}\right), \quad n \geq 0,
\end{array}\right.
$$


where $\left\{\alpha_{n}\right\},\left\{\beta_{n}\right\}$, and $\left\{\gamma_{n}\right\}$ are three sequences in $(0,1)$. Suppose the sequences $\left\{\alpha_{n}\right\},\left\{\beta_{n}\right\}$, and $\left\{\gamma_{n}\right\}$ satisfy the following conditions:

(i) $\quad \alpha_{n}+\beta_{n}+\gamma_{n}=1, \quad \forall n \geq 0$;

(ii) $\quad \lim _{n \rightarrow \infty} \alpha_{n}=0, \quad \sum_{n=1}^{\infty} \alpha_{n}=\infty$;

(iii) $\quad 0<\liminf _{n \rightarrow \infty} \beta_{n} \leq \limsup _{n \rightarrow \infty} \beta_{n}<1$.

Then $\left\{x_{n}\right\}$ converges strongly to $Q^{\prime} u$, where $Q^{\prime}$ is the sunny nonexpansive retraction of $C$ onto $\Omega$.

In 2013, Cai and $\mathrm{Bu}$ [4] introduced the system of a general variational inequalities problem for finding $\left(x^{*}, y^{*}\right) \in C \times C$ such that

$$
\begin{cases}\left\langle\lambda A y^{*}+x^{*}-y^{*}, j\left(x-x^{*}\right)\right\rangle \geq 0, & \forall x \in C, \\ \left\langle\mu B x^{*}+y^{*}-x^{*}, j\left(x-y^{*}\right)\right\rangle \geq 0, & \forall x \in C,\end{cases}
$$

where $\lambda, \mu>0$. The set of solutions of (1.5) we denote by $\Omega^{\prime}$. If $\lambda=\mu=1$, then problem (1.5) reduces to (1.4). In Hilbert space (1.5) reduces to

$$
\begin{cases}\left\langle\lambda A y^{*}+x^{*}-y^{*}, x-x^{*}\right\rangle \geq 0, & \forall x \in C, \\ \left\langle\mu B x^{*}+y^{*}-x^{*}, x-y^{*}\right\rangle \geq 0, & \forall x \in C,\end{cases}
$$

which is introduced by Ceng et al. [5]. If $A=B$, then (1.6) reduces to a problem for finding $\left(x^{*}, y^{*}\right) \in C \times C$ such that

$$
\begin{cases}\left\langle\lambda A y^{*}+x^{*}-y^{*}, x-x^{*}\right\rangle \geq 0, & \forall x \in C, \\ \left\langle\mu A x^{*}+y^{*}-x^{*}, x-y^{*}\right\rangle \geq 0, & \forall x \in C,\end{cases}
$$

which is introduced by Verma [6]. If $x^{*}=y^{*}$, then problem (1.7) reduces to the variational inequality for finding $x^{*} \in C$ such that

$$
\left\langle A x^{*}, y-x^{*}\right\rangle \geq 0, \quad \forall x \in C .
$$

Variational inequality theory is one of very important mathematical tools for solving many problems in economic, engineering, physical, pure and applied science etc.

Many authors have studied the iterative scheme for finding the solutions of a variational inequality problem; see for example [7-10].

By using the extragradient methods, Cai and $\mathrm{Bu}[4]$ proved a strong convergence theorem for finding the solutions of (1.5) as follows.

Theorem 1.3 Let $C$ be a nonempty closed convex subset of a 2-uniformly smooth and uniformly convex Banach space $E$ such that $C \pm C \subset C$. Let $P_{C}$ be the sunny nonexpansive retraction from $E$ to $C$. Let the mapping $A, B: C \rightarrow E$ be $\alpha$-inverse strongly accretive and $\beta$-inverse strongly accretive, respectively. Let $\left\{T_{i}: C \rightarrow C\right\}_{i=0}^{\infty}$ be an infinite family of nonexpansive mapping with $F=\bigcap_{i=0}^{\infty} \cap \Omega^{\prime} \neq \emptyset$. Let $S: C \rightarrow C$ be a nonexpansive mapping and 
$D: C \rightarrow C$ be a strongly positive linear bounded operator with the coefficient $\bar{\gamma}$ such that $0<\gamma<\bar{\gamma}$. For arbitrarily given $x_{0} \in C$, let the sequence $\left\{x_{n}\right\}$ be generated iteratively by

$$
\left\{\begin{array}{l}
z_{n}=P_{C}\left(x_{n}-\mu B x_{n}\right), \\
k_{n}=P_{C}\left(z_{n}-\lambda A z_{n}\right), \\
y_{n}=\left(1-\beta_{n}\right) x_{n}+\beta_{n} k_{n}, \\
x_{n+1}=\alpha_{n} \gamma S y_{n}+\gamma_{n} x_{n}+\left(\left(1-\gamma_{n} I-\alpha_{n} D\right)\right) T_{n} y_{n},
\end{array}\right.
$$

where $0<\lambda<\frac{\alpha}{K^{2}}$ and $0<\mu<\frac{\beta}{K^{2}}$. Assume that $\left\{\alpha_{n}\right\},\left\{\beta_{n}\right\}$, and $\left\{\gamma_{n}\right\}$ are three sequences in $[0,1]$ satisfying the following conditions:

(i) $\quad \lim _{n \rightarrow \infty} \alpha_{n}=0, \quad \sum_{n=0}^{\infty} \alpha_{n}=\infty$;

(ii) $\quad 0<\liminf _{n \rightarrow \infty} \gamma_{n} \leq \limsup _{n \rightarrow \infty} \gamma_{n}<1$;

(iii) $\quad \lim _{n \rightarrow \infty}\left|\beta_{n+1}-\beta_{n}\right|=0, \quad \liminf _{n \rightarrow \infty} \beta_{n}>0$.

Suppose that for any bounded subset $D^{\prime}$ of $C$ there exists an increasing, continuous, and convex function $h_{D^{\prime}}$ from $\mathbb{R}^{+} \rightarrow \mathbb{R}^{+}$such that $h_{D^{\prime}}(0)=0$ and $\lim _{k, l \rightarrow \infty} \sup \left\{h_{D^{\prime}}\left(\left\|T_{k} z-T_{l} z\right\|\right)\right.$ : $\left.z \in D^{\prime}\right\}=0$. Let $T$ be a mapping from $C$ into $C$ defined by $T x=\lim _{n \rightarrow \infty} T_{n} x$ for all $x \in C$ and suppose that $F(T)=\bigcap_{i=0}^{\infty} F\left(T_{i}\right)$. Then $\left\{x_{n}\right\}$ converges strongly to $z \in F$, which also solves the following variational inequality:

$$
\langle\gamma S z-D z, j(p-z)\rangle \leq 0, \quad \forall p \in F
$$

For the research related to the extragradient methods, some additional references are [11-13].

Motivated by (1.4) and (1.5), we introduce the problem for finding $\left(x^{*}, y^{*}\right) \in C \times C$ such that

$$
\left\{\begin{array}{l}
\left\langle x^{*}-\left(I-\lambda_{A} A\right)\left(a x^{*}+(1-a) y^{*}\right), j\left(x-x^{*}\right)\right\rangle \geq 0 \\
\left\langle y^{*}-\left(I-\lambda_{B} B\right) x^{*}, j\left(x-y^{*}\right)\right\rangle \geq 0
\end{array}\right.
$$

for all $x \in C, \lambda_{A}, \lambda_{B}>0$ and $a \in[0,1]$. This problem is called the modification of a system of variational inequalities problems in Banach space. If $a=0$, then (1.8) reduces to (1.5).

Motivated by Theorems 1.2 and 1.3, we use the methods different from extragradient methods to prove a strong convergence theorem for finding the solutions of (1.8) and an element of the set of fixed points of two finite families of nonexpansive and strictly pseudocontractive mappings in a uniformly convex and 2-uniformly smooth Banach space. Applying the main result, we obtain a strong convergence theorem involving two sets of solutions of variational inequalities problems introduced by Aoyama et al. [14] in a uniformly convex and 2-uniformly smooth Banach space. Moreover, we also give a numerical example to support our main results in the last section.

\section{Preliminaries}

The following lemmas and definitions are important tools to prove the results in the next sections. 
Definition 2.1 ([15]) Let $C$ be a nonempty convex subset of a Banach space. Let $\left\{S_{i}\right\}_{i=1}^{N}$ and $\left\{T_{i}\right\}_{i=1}^{N}$ be two finite families of mappings of $C$ into itself. For each $j=1,2, \ldots, N$, let $\alpha_{j}=\left(\alpha_{1}^{j}, \alpha_{2}^{j}, \alpha_{3}^{j}\right) \in I \times I \times I$, where $I \in[0,1]$ and $\alpha_{1}^{j}+\alpha_{2}^{j}+\alpha_{3}^{j}=1$. Define the mapping $S^{A}$ : $C \rightarrow C$ as follows:

$$
\begin{aligned}
& U_{0}=T_{1}=I, \\
& U_{1}=T_{1}\left(\alpha_{1}^{1} S_{1} U_{0}+\alpha_{2}^{1} U_{0}+\alpha_{3}^{1} I\right), \\
& U_{2}=T_{2}\left(\alpha_{1}^{2} S_{2} U_{1}+\alpha_{2}^{2} U_{1}+\alpha_{3}^{2} I\right), \\
& U_{3}=T_{3}\left(\alpha_{1}^{3} S_{3} U_{2}+\alpha_{2}^{3} U_{2}+\alpha_{3}^{3} I\right), \\
& \vdots \\
& U_{N-1}=T_{N-1}\left(\alpha_{1}^{N-1} S_{N-1} U_{N-2}+\alpha_{2}^{N-1} U_{N-2}+\alpha_{3}^{N-1} I\right), \\
& S^{A}=U_{N}=T_{N}\left(\alpha_{1}^{N} S_{N} U_{N-1}+\alpha_{2}^{N} U_{N-1}+\alpha_{3}^{N} I\right) .
\end{aligned}
$$

This mapping is called the $S^{A}$-mapping generated by $S_{1}, S_{2}, \ldots, S_{N}, T_{1}, T_{2}, \ldots, T_{N}$, and $\alpha_{1}, \alpha_{2}, \ldots, \alpha_{N}$.

Lemma 2.1 ([15]) Let $C$ be a nonempty closed convex subset of a uniformly convex and 2-uniformly smooth Banach space. Let $\left\{S_{i}\right\}_{i=1}^{N}$ be a finite family of $\kappa_{i}$-strict pseudocontractions of $C$ into itself and let $\left\{T_{i}\right\}_{i=1}^{N}$ be a finite family of nonexpansive mappings of $C$ into itself with $\bigcap_{i=1}^{N} F\left(S_{i}\right) \cap \bigcap_{i=1}^{N} F\left(T_{i}\right) \neq \emptyset$ and $\kappa=\min \left\{\kappa_{i}: i=1,2, \ldots, N\right\}$ with $K^{2} \leq \kappa$, where $K$ is the 2-uniformly smooth constant of E. Let $\alpha_{j}=\left(\alpha_{1}^{j}, \alpha_{2}^{j}, \alpha_{3}^{j}\right) \in I \times I \times I$, where $I=[0,1], \alpha_{1}^{j}+\alpha_{2}^{j}+\alpha_{3}^{j}=1, \alpha_{1}^{j} \in(0,1], \alpha_{2}^{j} \in[0,1]$ and $\alpha_{3}^{j} \in(0,1)$ for all $j=1,2, \ldots, N$. Let $S^{A}$ be the $S^{A}$-mapping generated by $S_{1}, S_{2}, \ldots, S_{N}, T_{1}, T_{2}, \ldots, T_{N}$, and $\alpha_{1}, \alpha_{2}, \ldots, \alpha_{N}$. Then $F\left(S^{A}\right)=\bigcap_{i=1}^{N} F\left(S_{i}\right) \cap \bigcap_{i=1}^{N} F\left(T_{i}\right)$ and $S^{A}$ is a nonexpansive mapping.

Lemma 2.2 ([16]) Let $\left\{s_{n}\right\}$ be a sequence of nonnegative real numbers satisfying

$$
s_{n+1} \leq\left(1-\alpha_{n}\right) s_{n}+\delta_{n}, \quad \forall n \geq 0,
$$

where $\left\{\alpha_{n}\right\}$ is a sequence in $(0,1)$ and $\left\{\delta_{n}\right\}$ is a sequence such that

$$
\begin{aligned}
& \text { (1) } \sum_{n=1}^{\infty} \alpha_{n}=\infty, \\
& \text { (2) } \limsup _{n \rightarrow \infty} \frac{\delta_{n}}{\alpha_{n}} \leq 0 \quad \text { or } \quad \sum_{n=1}^{\infty}\left|\delta_{n}\right|<\infty \text {. }
\end{aligned}
$$

Then $\lim _{n \rightarrow \infty} s_{n}=0$.

Lemma 2.3 ([17]) Let E be a real 2-uniformly smooth Banach space with the best smooth constant $K$. Then the following inequality holds:

$$
\|x+y\|^{2} \leq\|x\|^{2}+2\langle y, J(x)\rangle+2\|K y\|^{2}
$$

for any $x, y \in E$. 
Lemma 2.4 ([18]) Let $C$ be a nonempty closed convex subset of a uniformly convex and uniformly smooth Banach space $E$ and let $T$ be a nonexpansive mapping of $C$ into itself with $F(T) \neq \emptyset$. Then $F(T)$ is a sunny nonexpansive retract of $C$.

Lemma 2.5 ([19]) Let C be a nonempty closed convex subset of a smooth Banach space and $Q_{C}$ be a retraction from $E$ onto $C$. Then the following are equivalent:

(i) $Q_{C}$ is both sunny and nonexpansive;

(ii) $\left\langle x-Q_{C} x, J\left(y-Q_{C} x\right)\right\rangle \leq 0$ for all $x \in E$ and $y \in C$.

It is obvious that if $E$ is a Hilbert space, we find that a sunny nonexpansive retraction $Q_{C}$ is coincident with the metric projection from $E$ onto $C$. From Lemma 2.5, let $x \in E$ and $x_{0} \in C$. Then we have $x_{0}=Q_{C} x$ if and only if $\left\langle x-x_{0}, J\left(y-x_{0}\right)\right\rangle \leq 0$, for all $y \in C$, where $Q_{C}$ is a sunny nonexpansive retraction from $E$ onto $C$.

Lemma 2.6 ([20]) Let E be a uniformly convex Banach space and $B_{r}=\{x \in E:\|x\| \leq r\}$, $r>0$. Then there exists a continuous, strictly increasing, and convex function $g:[0, \infty] \rightarrow$ $[0, \infty], g(0)=0$ such that

$$
\|\alpha x+\beta y+\gamma z\|^{2} \leq \alpha\|x\|^{2}+\beta\|y\|^{2}+\gamma\|z\|^{2}-\alpha \beta g(\|x-y\|)
$$

for all $x, y, z \in B_{r}$ and all $\alpha, \beta, \gamma \in[0,1]$ with $\alpha+\beta+\gamma=1$.

Lemma 2.7 ([21]) Let $C$ be a closed and convex subset of a real uniformly smooth Banach space $E$ and let $T: C \rightarrow C$ be a nonexpansive mapping with a nonempty fixed point $F(T)$. If $\left\{x_{n}\right\} \subset C$ is a bounded sequence such that $\lim _{n \rightarrow \infty}\left\|x_{n}-T x_{n}\right\|=0$. Then there exists a unique sunny nonexpansive retraction $Q_{F(T)}: C \rightarrow F(T)$ such that

$$
\limsup _{n \rightarrow \infty}\left\langle u-Q_{F(T)} u, J\left(x_{n}-Q_{F(T)} u\right)\right\rangle \leq 0
$$

for any given $u \in C$.

Lemma 2.8 ([17]) Let $r>0$. If $E$ is uniformly convex, then there exists a continuous, strictly increasing, and convex function $g:[0, \infty) \rightarrow[0, \infty), g(0)=0$ such that for all $x, y \in B_{r}(0)=$ $\{x \in E:\|x\| \leq r\}$ and for any $\alpha \in[0,1]$, we have $\|\alpha x+(1-\alpha) y\|^{2} \leq \alpha\|x\|^{2}+(1-\alpha)\|y\|^{2}-$ $\alpha(1-\alpha) g(\|x-y\|)$.

Lemma 2.9 ([22]) Let $C$ be a closed convex subset of a strictly convex Banach space E. Let $T_{1}$ and $T_{2}$ be two nonexpansive mappings from $C$ into itself with $F\left(T_{1}\right) \cap F\left(T_{2}\right) \neq \emptyset$. Define a mapping $S$ by

$$
S x=\lambda T_{1} x+(1-\lambda) T_{2} x, \quad \forall x \in C,
$$

where $\lambda$ is a constant in $(0,1)$. Then $S$ is nonexpansive and $F(S)=F\left(T_{1}\right) \cap F\left(T_{2}\right)$.

Lemma 2.10 Let $C$ be a nonempty closed convex subset of a smooth Banach space $E$ and let $A, B: C \rightarrow E$ be mappings. Let $Q_{C}$ be a sunny nonexpansive retraction of $E$ onto $C$. For every $\lambda_{A}, \lambda_{B}>0$ and $a \in[0,1]$. The following are equivalent: 
(a) $\left(x^{*}, z^{*}\right)$ is a solution of $(1.8)$;

(b) $x^{*}$ is a fixed point of mapping $G: C \rightarrow C$, i.e., $x^{*} \in F(G)$, defined by

$$
G x=Q_{C}\left(I-\lambda_{A} A\right)\left(a I+(1-a) Q_{C}\left(I-\lambda_{B} B\right)\right) x, \quad \forall x \in C,
$$

where $z^{*}=Q_{C}\left(I-\lambda_{B} B\right) x^{*}$.

Proof First we show that (a) $\Rightarrow(\mathrm{b})$. Let $\left(x^{*}, z^{*}\right)$ is a solution of $(1.8)$, and we have

$$
\left\{\begin{array}{l}
\left\langle x^{*}-\left(I-\lambda_{A} A\right)\left(a x^{*}+(1-a) z^{*}\right), j\left(x-x^{*}\right)\right\rangle \geq 0, \\
\left\langle z^{*}-\left(I-\lambda_{B} B\right) x^{*}, j\left(x-z^{*}\right)\right\rangle \geq 0
\end{array}\right.
$$

for all $x \in C$. From Lemma 2.5, we have

$$
x^{*}=Q_{C}\left(I-\lambda_{A} A\right)\left(a x^{*}+(1-a) z^{*}\right)
$$

and $z^{*}=Q_{C}\left(I-\lambda_{B} B\right) x^{*}$.

It follows that

$$
x^{*}=Q_{C}\left(I-\lambda_{A} A\right)\left(a x^{*}+(1-a) Q_{C}\left(I-\lambda_{B} B\right) x^{*}\right)=G x^{*} .
$$

Then $x^{*} \in F(G)$, where $z^{*}=Q_{C}\left(I-\lambda_{B} B\right) x^{*}$.

Next we claim that $(\mathrm{b}) \Rightarrow(\mathrm{a})$. Let $x^{*} \in F(G)$ and $z^{*}=Q_{C}\left(I-\lambda_{B} B\right) x^{*}$. Then

$$
x^{*}=G x^{*}=Q_{C}\left(I-\lambda_{A} A\right)\left(a x^{*}+(1-a) Q_{C}\left(I-\lambda_{B} B\right) x^{*}\right)=Q_{C}\left(I-\lambda_{A} A\right)\left(a x^{*}+(1-a) z^{*}\right) .
$$

From Lemma 2.5, we have

$$
\left\{\begin{array}{l}
\left\langle x^{*}-\left(I-\lambda_{A} A\right)\left(a x^{*}+(1-a) z^{*}\right), j\left(x-x^{*}\right)\right\rangle \geq 0 \\
\left\langle z^{*}-\left(I-\lambda_{B} B\right) x^{*}, j\left(x-z^{*}\right)\right\rangle \geq 0
\end{array}\right.
$$

for all $x \in C$. Then we find that $\left(x^{*}, z^{*}\right)$ is a solution of (1.8).

Example 2.1 Let $\mathbb{R}$ be a real line with the Euclidean norm and let $A, B: \mathbb{R} \rightarrow \mathbb{R}$ defined by $A x=\frac{x-1}{4}$ and $B x=\frac{x-1}{2}$ for all $x \in \mathbb{R}$. The mapping $G: \mathbb{R} \rightarrow \mathbb{R}$ defined by

$$
G x=(I-2 A)\left(\frac{1}{2} I+\frac{1}{2}(I-3 B)\right) x
$$

for all $x \in \mathbb{R}$. Then $1 \in F(G)$ and $(1,1)$ is a solution of $(1.8)$.

\section{Main results}

Theorem 3.1 Let $C$ be a nonempty closed convex subset of a uniformly convex and 2-uniformly smooth Banach space $E$ and let $Q_{C}$ be a sunny nonexpansive retraction of $E$ onto $C$. Let $A, B: C \rightarrow E$ be $\alpha$ - and $\beta$-inverse strongly accretive operators, respectively. Define the mapping $G: C \rightarrow C$ by $G x=Q_{C}\left(I-\lambda_{A} A\right)\left(a I+(1-a) Q_{C}\left(I-\lambda_{B} B\right)\right) x$ for all $x \in C$, $\lambda_{A} \in\left(0, \frac{\alpha}{K^{2}}\right), \lambda_{B} \in\left(0, \frac{\beta}{K^{2}}\right)$ and $a \in[0,1]$, where $K$ is the 2-uniformly smooth constant of $E$. 
Let $\left\{S_{i}\right\}_{i=1}^{N}$ be a finite family of $\kappa_{i}$-strict pseudo-contractions of C into itself and let $\left\{T_{i}\right\}_{i=1}^{N}$ be a finite family of nonexpansive mappings of C into itself and $\kappa=\min \left\{\kappa_{i}: i=1,2, \ldots, N\right\}$ with $K^{2} \leq \kappa$. Let $\alpha_{j}=\left(\alpha_{1}^{j}, \alpha_{2}^{j}, \alpha_{3}^{j}\right) \in I \times I \times I$, where $I=[0,1], \alpha_{1}^{j}+\alpha_{2}^{j}+\alpha_{3}^{j}=1, \alpha_{1}^{j} \in(0,1], \alpha_{2}^{j} \in[0,1]$, and $\alpha_{3}^{j} \in(0,1)$ for all $j=1,2, \ldots, N$. Let $S^{A}$ be the $S^{A}$-mapping generated by $S_{1}, S_{2}, \ldots, S_{N}$, $T_{1}, T_{2}, \ldots, T_{N}$, and $\alpha_{1}, \alpha_{2}, \ldots, \alpha_{N}$. Assume that $\mathcal{F}=F(G) \cap \bigcap_{i=1}^{N} F\left(S_{i}\right) \cap \bigcap_{i=1}^{N} F\left(T_{i}\right) \neq \emptyset$. Let the sequence $\left\{x_{n}\right\}$ be generated by $u, x_{1} \in C$ and

$$
x_{n+1}=G\left(\alpha_{n} u+\beta_{n} x_{n}+\gamma_{n} S^{A} x_{n}\right), \quad \forall n \geq 1,
$$

where $\left\{\alpha_{n}\right\},\left\{\beta_{n}\right\},\left\{\gamma_{n}\right\} \subseteq[0,1]$ with $\alpha_{n}+\beta_{n}+\gamma_{n}=1$. Suppose that the following conditions are satisfied:

(i) $\quad \lim _{n \rightarrow \infty} \alpha_{n}=0, \quad \sum_{n=1}^{\infty} \alpha_{n}=\infty$;

(ii) $0<c \leq \beta_{n} \leq d<1$ for some $c, d>0$ and for all $n \geq 1$;

(iii) $\sum_{n=1}^{\infty}\left|\beta_{n+1}-\beta_{n}\right|, \sum_{n=1}^{\infty}\left|\alpha_{n+1}-\alpha_{n}\right|<\infty$.

Then the sequence $\left\{x_{n}\right\}$ converges strongly to $x_{0}=Q_{\mathcal{F}} u$ and $\left(x_{0}, z_{0}\right)$ is a solution of (1.8), where $z_{0}=Q_{C}\left(I-\lambda_{B} B\right) x_{0}$.

Proof First, we show that $Q_{C}\left(I-\lambda_{A} A\right)$ and $Q_{C}\left(I-\lambda_{B} B\right)$ are nonexpansive mappings. Let $x, y \in C$; we have

$$
\begin{aligned}
& \left\|Q_{C}\left(I-\lambda_{A} A\right) x-Q_{C}\left(I-\lambda_{A} A\right) y\right\|^{2} \\
& \quad \leq\left\|x-y-\lambda_{A}(A x-A y)\right\|^{2} \\
& \quad \leq\|x-y\|^{2}-2 \lambda_{A}|A x-A y, j(x-y)\rangle+2 K^{2} \lambda_{A}^{2}\|A x-A y\|^{2} \\
& \quad \leq\|x-y\|^{2}-2 \lambda_{A} \alpha\|A x-A y\|^{2}+2 K^{2} \lambda_{A}^{2}\|A x-A y\|^{2} \\
& \quad \leq\|x-y\|^{2}-2 \lambda_{A}\left(\alpha-K^{2} \lambda_{A}\right)\|A x-A y\|^{2} \\
& \quad \leq\|x-y\|^{2} .
\end{aligned}
$$

Then $Q_{C}\left(I-\lambda_{A} A\right)$ is a nonexpansive mapping. By using the same method we find that $Q_{C}\left(I-\lambda_{B} B\right)$ is a nonexpansive mapping. From the definition of $G$, we see that $G$ is a nonexpansive mapping. Let $x^{*} \in \mathcal{F}$. Put $y_{n}=\alpha_{n} u+\beta_{n} x_{n}+\gamma_{n} S^{A} x_{n}$ for all $n \geq 1$. From the definition of $x_{n}$ and Lemma 2.10, we have

$$
\begin{aligned}
\left\|x_{n+1}-x^{*}\right\| & =\left\|G y_{n}-x^{*}\right\| \\
& \leq\left\|y_{n}-x^{*}\right\| \\
& =\left\|\alpha_{n}\left(u-x^{*}\right)+\beta_{n}\left(x_{n}-x^{*}\right)+\gamma_{n}\left(S^{A} x_{n}-x^{*}\right)\right\| \\
& \leq \alpha_{n}\left\|u-x^{*}\right\|+\beta_{n}\left\|x_{n}-x^{*}\right\|+\gamma_{n}\left\|S^{A} x_{n}-x^{*}\right\| \\
& \leq \alpha_{n}\left\|u-x^{*}\right\|+\left(1-\alpha_{n}\right)\left\|x_{n}-x^{*}\right\| \\
& \leq \max \left\{\left\|u-x^{*}\right\|,\left\|x_{1}-x^{*}\right\|\right\} .
\end{aligned}
$$


Applying mathematical induction, we can conclude that the sequence $\left\{x_{n}\right\}$ is bounded and so is $\left\{y_{n}\right\}$.

From the definition of $x_{n}$, we have

$$
\begin{aligned}
\left\|x_{n+1}-x_{n}\right\|= & \left\|G y_{n}-G y_{n-1}\right\| \\
\leq & \left\|\alpha_{n} u+\beta_{n} x_{n}+\gamma_{n} S^{A} x_{n}-\alpha_{n-1} u-\beta_{n-1} x_{n-1}-\gamma_{n-1} S^{A} x_{n-1}\right\| \\
\leq & \left|\alpha_{n}-\alpha_{n-1}\right|\|u\|+\beta_{n}\left\|x_{n}-x_{n-1}\right\|+\left|\beta_{n}-\beta_{n-1}\right|\left\|x_{n-1}\right\| \\
& +\gamma_{n}\left\|S^{A} x_{n}-S^{A} x_{n-1}\right\|+\left|\gamma_{n}-\gamma_{n-1}\right|\left\|S^{A} x_{n-1}\right\| \\
\leq & \left(1-\alpha_{n}\right)\left\|x_{n}-x_{n-1}\right\|+\left|\alpha_{n}-\alpha_{n-1}\right|\|u\|+\left|\beta_{n}-\beta_{n-1}\right|\left\|x_{n-1}\right\| \\
& +\left|\gamma_{n}-\gamma_{n-1}\right|\left\|S^{A} x_{n-1}\right\| .
\end{aligned}
$$

Applying (3.2), the condition (iii), and Lemma 2.2, we have

$$
\lim _{n \rightarrow \infty}\left\|x_{n+1}-x_{n}\right\|=0
$$

From the definition of $x_{n}$, we have

$$
\begin{aligned}
\left\|x_{n+1}-x^{*}\right\|^{2} \leq & \left\|y_{n}-x^{*}\right\|^{2} \\
\leq & \alpha_{n}\left\|u-x^{*}\right\|^{2}+\beta_{n}\left\|x_{n}-x^{*}\right\|^{2}+\gamma_{n}\left\|S^{A} x_{n}-x^{*}\right\|^{2} \\
& \quad-\beta_{n} \gamma_{n} g\left(\left\|S^{A} x_{n}-x_{n}\right\|\right) \\
\leq & \alpha_{n}\left\|u-x^{*}\right\|^{2}+\left\|x_{n}-x^{*}\right\|^{2}-\beta_{n} \gamma_{n} g\left(\left\|S^{A} x_{n}-x_{n}\right\|\right) .
\end{aligned}
$$

It follows that

$$
\begin{aligned}
\beta_{n} \gamma_{n} g\left(\left\|S^{A} x_{n}-x_{n}\right\|\right) & \leq \alpha_{n}\left\|u-x^{*}\right\|^{2}+\left\|x_{n}-x^{*}\right\|^{2}-\left\|x_{n+1}-x^{*}\right\|^{2} \\
& \leq \alpha_{n}\left\|u-x^{*}\right\|^{2}+\left(\left\|x_{n}-x^{*}\right\|+\left\|x_{n+1}-x^{*}\right\|\right)\left\|x_{n+1}-x_{n}\right\| .
\end{aligned}
$$

From (3.3) and the conditions (i) and (ii), we have

$$
\lim _{n \rightarrow \infty} g\left(\left\|S^{A} x_{n}-x_{n}\right\|\right)=0
$$

From the property of $g$, we have

$$
\lim _{n \rightarrow \infty}\left\|S^{A} x_{n}-x_{n}\right\|=0
$$

From the definition of $y_{n}$, we have

$$
y_{n}-x_{n}=\alpha_{n}\left(u-x_{n}\right)+\gamma_{n}\left(S^{A} x_{n}-x_{n}\right) .
$$

From the condition (i) and (3.4), we obtain

$$
\lim _{n \rightarrow \infty}\left\|y_{n}-x_{n}\right\|=0
$$


From the definition of $y_{n}$, we have

$$
y_{n}-S^{A} x_{n}=\alpha_{n}\left(u-S^{A} x_{n}\right)+\beta_{n}\left(x_{n}-S^{A} x_{n}\right) .
$$

From the condition (i) and (3.4), we obtain

$$
\lim _{n \rightarrow \infty}\left\|y_{n}-S^{A} x_{n}\right\|=0
$$

From the nonexpansiveness of $S^{A}$, we have

$$
\begin{aligned}
\left\|S^{A} y_{n}-y_{n}\right\| & \leq\left\|S^{A} y_{n}-S^{A} x_{n}\right\|+\left\|S^{A} x_{n}-y_{n}\right\| \\
& \leq\left\|y_{n}-S^{A} x_{n}\right\|+\left\|x_{n}-y_{n}\right\| .
\end{aligned}
$$

From (3.5) and (3.6), we have

$$
\lim _{n \rightarrow \infty}\left\|S^{A} y_{n}-y_{n}\right\|=0
$$

From the definition of $x_{n}$, we have

$$
\begin{aligned}
\left\|G y_{n}-y_{n}\right\| & \leq\left\|G y_{n}-x_{n}\right\|+\left\|x_{n}-y_{n}\right\| \\
& =\left\|x_{n+1}-x_{n}\right\|+\left\|x_{n}-y_{n}\right\| .
\end{aligned}
$$

From (3.3) and (3.5), we have

$$
\lim _{n \rightarrow \infty}\left\|G y_{n}-y_{n}\right\|=0 .
$$

Define the mapping $B: C \rightarrow C$ by $B x=\epsilon G x+(1-\epsilon) S^{A} x$ for all $x \in C$ and $\epsilon \in(0,1)$. From Lemmas 2.1 and 2.9, we have $F(B)=F(G) \cap F\left(S^{A}\right)=F(G) \cap \bigcap_{i=1}^{N} F\left(T_{i}\right) \cap \bigcap_{i=1}^{N} F\left(S_{i}\right)=\mathcal{F}$. From the definition of $B$, (3.7) and (3.8), we have

$$
\lim _{n \rightarrow \infty}\left\|y_{n}-B y_{n}\right\|=0
$$

Since $G$ and $S^{A}$ are nonexpansive mappings, we have $B$ is a nonexpansive mapping. From Lemma 2.7, we have

$$
\limsup _{n \rightarrow \infty}\left\langle u-x_{0}, j\left(y_{n}-x_{0}\right)\right\rangle \leq 0,
$$

where $x_{0}=Q_{\mathcal{F}} u$.

Finally, we show that the sequence $\left\{x_{n}\right\}$ converges strongly to $x_{0}=Q_{\mathcal{F}} u$. From the definition of $x_{n}$, we have

$$
\begin{aligned}
\left\|x_{n+1}-x_{0}\right\|^{2} & \leq\left\|y_{n}-x_{0}\right\|^{2} \\
& =\left\|\alpha_{n}\left(u-x_{0}\right)+\beta_{n}\left(x_{n}-x_{0}\right)+\gamma_{n}\left(S^{A} x_{n}-x_{0}\right)\right\|^{2} \\
& \leq\left\|\beta_{n}\left(x_{n}-x_{0}\right)+\gamma_{n}\left(S^{A} x_{n}-x_{0}\right)\right\|^{2}+2 \alpha_{n}\left\langle u-x_{0}, j\left(y_{n}-x_{0}\right)\right\rangle \\
& \leq\left(1-\alpha_{n}\right)\left\|x_{n}-x_{0}\right\|^{2}+2 \alpha_{n}\left\langle u-x_{0}, j\left(y_{n}-x_{0}\right)\right\rangle .
\end{aligned}
$$


Applying Lemma 2.2, the condition (i) and (3.10), we can conclude that the sequence $\left\{x_{n}\right\}$ converges strongly to $x_{0}=Q_{\mathcal{F}} u$ and $\left(x_{0}, z_{0}\right)$ is a solution of $(1.8)$, where $z_{0}=Q_{C}\left(I-\lambda_{B} B\right) x_{0}$. This completes the proof.

The following corollary is a strong convergence theorem involving problem (1.5). This result is a direct proof from Theorem 3.1. We, therefore, omit the proof.

Corollary 3.2 Let $C$ be a nonempty closed convex subset of a uniformly convex and 2-uniformly smooth Banach space $E$ and let $Q_{C}$ be a sunny nonexpansive retraction of $E$ onto $C$. Let $A, B: C \rightarrow E$ be $\alpha$ - and $\beta$-inverse strongly accretive operators, respectively. Define the mapping $G: C \rightarrow C$ by $G x=Q_{C}\left(I-\lambda_{A} A\right)\left(Q_{C}\left(I-\lambda_{B} B\right)\right) x$ for all $x \in C$, $\lambda_{A} \in\left(0, \frac{\alpha}{K^{2}}\right), \lambda_{B} \in\left(0, \frac{\beta}{K^{2}}\right)$, where $K$ is the 2-uniformly smooth constant of $E$. Let $\left\{S_{i}\right\}_{i=1}^{N}$ be a finite family of $\kappa_{i}$-strict pseudo-contractions of $C$ into itself and let $\left\{T_{i}\right\}_{i=1}^{N}$ be a finite family of nonexpansive mappings of $C$ into itself and $\kappa=\min \left\{\kappa_{i}: i=1,2, \ldots, N\right\}$ with $K^{2} \leq \kappa$. Let $\alpha_{j}=\left(\alpha_{1}^{j}, \alpha_{2}^{j}, \alpha_{3}^{j}\right) \in I \times I \times I$, where $I=[0,1], \alpha_{1}^{j}+\alpha_{2}^{j}+\alpha_{3}^{j}=1, \alpha_{1}^{j} \in(0,1], \alpha_{2}^{j} \in[0,1]$, and $\alpha_{3}^{j} \in(0,1)$ for all $j=1,2, \ldots, N$. Let $S^{A}$ be the $S^{A}$-mapping generated by $S_{1}, S_{2}, \ldots, S_{N}$, $T_{1}, T_{2}, \ldots, T_{N}$, and $\alpha_{1}, \alpha_{2}, \ldots, \alpha_{N}$. Assume that $\mathcal{F}=F(G) \bigcap_{i=1}^{N} F\left(S_{i}\right) \cap \bigcap_{i=1}^{N} F\left(T_{i}\right) \neq \emptyset$. Let the sequence $\left\{x_{n}\right\}$ be generated by $u, x_{1} \in C$ and

$$
x_{n+1}=G\left(\alpha_{n} u+\beta_{n} x_{n}+\gamma_{n} S^{A} x_{n}\right), \quad \forall n \geq 1,
$$

where $\left\{\alpha_{n}\right\},\left\{\beta_{n}\right\},\left\{\gamma_{n}\right\} \subseteq[0,1]$ with $\alpha_{n}+\beta_{n}+\gamma_{n}=1$. Suppose that the following conditions are satisfied:

$$
\begin{aligned}
& \text { (i) } \lim _{n \rightarrow \infty} \alpha_{n}=0, \quad \sum_{n=1}^{\infty} \alpha_{n}=\infty \text {; } \\
& \text { (ii) } 0<c \leq \beta_{n} \leq d<1 \quad \text { for some } c, d>0 \text { and for all } n \geq 1 \text {; } \\
& \text { (iii) } \sum_{n=1}^{\infty}\left|\beta_{n+1}-\beta_{n}\right|, \sum_{n=1}^{\infty}\left|\alpha_{n+1}-\alpha_{n}\right|<\infty
\end{aligned}
$$

Then the sequence $\left\{x_{n}\right\}$ converges strongly to $x_{0}=Q_{\mathcal{F}} u$ and $\left(x_{0}, z_{0}\right)$ is a solution of (1.5), where $z_{0}=Q_{C}\left(I-\lambda_{B} B\right) x_{0}$.

\section{Applications}

In this section, we prove a strong convergence theorem involving two sets of solutions of variational inequalities in Banach space. We give some useful lemmas and definitions to prove Theorem 4.4.

Let $A: C \rightarrow E$ be a mapping. The variational inequality problem in a Banach space is to find a point $x^{*} \in C$ such that for some $j\left(x-x^{*}\right) \in J\left(x-x^{*}\right)$,

$$
\left\langle A x^{*}, j\left(x-x^{*}\right)\right\rangle \geq 0, \quad \forall x \in C .
$$

This problem was considered by Aoyama et al. [14]. The set of solutions of the variational inequality in a Banach space is denoted by $S(C, A)$, that is,

$$
S(C, A)=\{u \in C:\langle A u, J(v-u)| \geq 0, \forall v \in C\} .
$$


The variational inequalities problems have been studied by many authors; see, for example, $[11,23]$.

Lemma 4.1 ([14]) Let $C$ be a nonempty closed convex subset of a smooth Banach space E. Let $Q_{C}$ be a sunny nonexpansive retraction from $E$ onto $C$ and let $A$ be an accretive operator of $C$ into $E$. Then, for all $\lambda>0$,

$$
S(C, A)=F\left(Q_{C}(I-\lambda A)\right) .
$$

Lemma 4.2 Let $C$ be a nonempty closed convex subset of a uniformly convex Banach space E. Let $T, S: C \rightarrow C$ be nonexpansive mappings with $F(T) \cap F(S) \neq \emptyset$. Define the mapping $T_{a}: C \rightarrow C$ by $T_{a} x=S(a x+(1-a) T x)$ for all $x \in C$ and $a \in(0,1)$. Then $F\left(T_{a}\right)=$ $F(T) \cap F(S)$ and $T_{a}$ is a nonexpansive mapping.

Proof It is easy to see that $F(T) \cap F(S) \subseteq F\left(T_{a}\right)$. Let $x_{0} \in F\left(T_{a}\right)$ and $x^{*} \in F(S) \cap F(T)$. From the definition of $T_{a}$, we have

$$
\begin{aligned}
\left\|x_{0}-x^{*}\right\|^{2} & \leq\left\|a\left(x_{0}-x^{*}\right)+(1-a)\left(T x_{0}-x^{*}\right)\right\|^{2} \\
& \leq a\left\|x_{0}-x^{*}\right\|^{2}+(1-a)\left\|T x_{0}-x^{*}\right\|^{2}-a(1-a) g\left(\left\|x_{0}-T x_{0}\right\|\right) \\
& \leq\left\|x_{0}-x^{*}\right\|^{2}-a(1-a) g\left(\left\|x_{0}-T x_{0}\right\|\right) .
\end{aligned}
$$

It follows that

$$
g\left(\left\|x_{0}-T x_{0}\right\|\right)=0
$$

Applying the property of $g$, we have $x_{0}=T x_{0}$, that is, $x_{0} \in F(T)$. Since $x_{0} \in F\left(T_{a}\right)$ and $x_{0} \in F(T)$, we have

$$
x_{0}=S\left(a x_{0}+(1-a) T x_{0}\right)=S x_{0} .
$$

It follows that $x_{0} \in F(S)$. Hence $F\left(T_{a}\right) \subseteq F(T) \cap F(S)$. Applying (4.3), we have $T_{a}$ is a nonexpansive mapping.

Lemma 4.3 Let $C$ be a nonempty closed convex subset of a uniformly convex and 2-uniformly smooth Banach space $E$ and let $Q_{C}$ be a sunny nonexpansive retraction from $E$ onto $C$. Let $A, B: C \rightarrow E$ be $\alpha$ - and $\beta$-inverse strongly accretive operators, respectively. Define a mapping $G$ as in Lemma 2.10 and for every $\lambda_{A} \in\left(0, \frac{\alpha}{K^{2}}\right), \lambda_{B} \in\left(0, \frac{\beta}{K^{2}}\right)$ and $a \in(0,1)$ where $K$ is 2-uniformly smooth constant. If $S(C, A) \cap S(C, B) \neq \emptyset$, then $F(G)=S(C, A) \cap S(C, B)$.

Proof From Lemma 4.1, we have

$$
S(C, A)=F\left(Q_{C}\left(I-\lambda_{A} A\right)\right) \quad \text { and } \quad S(C, B)=F\left(Q_{C}\left(I-\lambda_{B} B\right)\right) .
$$

Using the same method as Theorem 3.1, we find that $Q_{C}\left(I-\lambda_{A} A\right)$ and $Q_{C}\left(I-\lambda_{B} B\right)$ are nonexpansive mappings. 
From the definition of $G$ and Lemma 4.2, we have

$$
F(G)=F\left(Q_{C}\left(I-\lambda_{A} A\right)\right) \cap F\left(Q_{C}\left(I-\lambda_{B} B\right)\right)=S(C, A) \cap S(C, B) .
$$

From Theorem 3.1 and Lemma 4.3, we have the following theorem.

Theorem 4.4 Let $C$ be a nonempty closed convex subset of a uniformly convex and 2-uniformly smooth Banach space $E$ and let $Q_{C}$ be a sunny nonexpansive retraction of $E$ onto $C$. Let $A, B: C \rightarrow E$ be $\alpha$ - and $\beta$-inverse strongly accretive operators, respectively. Let $\left\{S_{i}\right\}_{i=1}^{N}$ be a finite family of $\kappa_{i}$-strict pseudo-contractions of $C$ into itself and let $\left\{T_{i}\right\}_{i=1}^{N}$ be a finite family of nonexpansive mappings of $C$ into itself and $\kappa=\min \left\{\kappa_{i}: i=1,2, \ldots, N\right\}$ with $K^{2} \leq \kappa$, where $K$ is the 2-uniformly smooth constant of $E$. Let $\alpha_{j}=\left(\alpha_{1}^{j}, \alpha_{2}^{j}, \alpha_{3}^{j}\right) \in I \times I \times I$, where $I=[0,1], \alpha_{1}^{j}+\alpha_{2}^{j}+\alpha_{3}^{j}=1, \alpha_{1}^{j} \in(0,1], \alpha_{2}^{j} \in[0,1]$, and $\alpha_{3}^{j} \in(0,1)$ for all $j=1,2, \ldots, N$. Let $S^{A}$ be the $S^{A}$-mapping generated by $S_{1}, S_{2}, \ldots, S_{N}, T_{1}, T_{2}, \ldots, T_{N}$, and $\alpha_{1}, \alpha_{2}, \ldots, \alpha_{N}$. Assume that $\mathcal{F}=S(C, A) \cap S(C, B) \bigcap_{i=1}^{N} F\left(S_{i}\right) \cap \bigcap_{i=1}^{N} F\left(T_{i}\right) \neq \emptyset$. Let the sequence $\left\{x_{n}\right\}$ be generated by $u, x_{1} \in C$, and

$$
\left\{\begin{array}{l}
y_{n}=\alpha_{n} u+\beta_{n} x_{n}+\gamma_{n} S^{A} x_{n}, \\
x_{n+1}=Q_{C}\left(I-\lambda_{A} A\right)\left(a I+(1-a) Q_{C}\left(I-\lambda_{B} B\right)\right) y_{n}, \quad \forall n \geq 1,
\end{array}\right.
$$

where $\left\{\alpha_{n}\right\},\left\{\beta_{n}\right\},\left\{\gamma_{n}\right\} \subseteq[0,1]$ and $a \in(0,1)$ with $\alpha_{n}+\beta_{n}+\gamma_{n}=1, \lambda_{A} \in\left(0, \frac{\alpha}{K^{2}}\right), \lambda_{B} \in\left(0, \frac{\beta}{K^{2}}\right)$. Suppose that the following conditions are satisfied:

(i) $\quad \lim _{n \rightarrow \infty} \alpha_{n}=0, \quad \sum_{n=1}^{\infty} \alpha_{n}=\infty$;

(ii) $0<c \leq \beta_{n} \leq d<1$ for some $c, d>0$ and for all $n \geq 1$;

(iii) $\sum_{n=1}^{\infty}\left|\beta_{n+1}-\beta_{n}\right|, \sum_{n=1}^{\infty}\left|\alpha_{n+1}-\alpha_{n}\right|<\infty$.

Then the sequence $\left\{x_{n}\right\}$ converges strongly to $x_{0}=Q_{\mathcal{F}} u$ and $\left(x_{0}, z_{0}\right)$ is a solution of (1.8), where $z_{0}=Q_{C}\left(I-\lambda_{B} B\right) x_{0}$.

From Theorem 4.4, we have the following result.

Example 4.1 Let $l^{2}=\left\{x=\left(x_{i}\right)_{i=1}^{\infty}: \sum_{i=1}^{\infty}\left|x_{i}\right|^{2}<\infty\right\}$ with norm define by $\|x\|=\left(\sum_{i=1}^{\infty}\left|x_{i}\right|\right)^{\frac{1}{2}}$. Define the mappings $A, B: l^{2} \rightarrow l^{2}$ by $A x=2 x$ and $B x=3 x$ for all $x=\left(x_{i}\right)_{i=1}^{\infty} \in l^{2}$.

For every $i=1,2, \ldots, 5$, define the mappings $S_{i}, T_{i}: l^{2} \rightarrow l^{2}$ by $S_{i} x=\frac{x}{2^{i}}$ and $T_{i} x=\frac{x}{3^{i}} x=$ $\left(x_{i}\right)_{i=1}^{\infty} \in l^{2}$. Let $S^{A}$ be $S^{A}$-mapping generated by $S_{1}, S_{2}, \ldots, S_{5}, T_{1}, T_{2}, \ldots, T_{5}$, and $\alpha_{1}, \alpha_{2}, \ldots, \alpha_{5}$ where $\alpha_{j}=\left(\alpha_{1}^{j}, \alpha_{2}^{j}, \alpha_{3}^{j}\right)$ for all $j=1,2, \ldots, 5$ and $\alpha_{1}^{j}=\alpha_{2}^{j}=\alpha_{3}^{j}=\frac{1}{3}$. Let the sequence $\left\{x_{n}\right\} \subseteq l^{2}$ be generated by $u, x_{1}=\left(x_{i}^{1}\right)_{i=1}^{\infty} \in l^{2}$ and

$$
\left\{\begin{array}{l}
y_{n}=\frac{1}{9 n} u+\frac{10 n-1}{18 n} x_{n}+\frac{8 n-1}{18 n} S^{A} x_{n}, \\
x_{n+1}=Q_{l^{2}}(I-4 A)\left(\frac{1}{4} I+\frac{3}{4} Q_{l^{2}}(I-3 B)\right) y_{n}, \quad \forall n \geq 1,
\end{array}\right.
$$

where $Q_{l^{2}}$ is a sunny nonexpansive retraction of $l^{2}$ onto $l^{2}$. Then the sequence $\left\{x_{n}\right\}$ converges strongly to 0 and $(0,0)$ is a solution of $(1.8)$. 
Remark 4.5 If $E=l_{p}(p \geq 2)$, then Theorem 4.4 also holds.

\section{Example and numerical results}

In this section, we give a numerical example to support the main result.

Example 5.1 Let $\mathbb{R}$ be the real line with Euclidean norm and let $C=\left[0, \frac{\pi}{2}\right]$ and $A, B: C \rightarrow$ $\mathbb{R}$ be mappings defined by $A x=\frac{x}{2}$ and $B x=\frac{x}{4}$ for all $x \in C$. For every $i=1,2, \ldots, N$, define the mapping $S_{i}, T_{i}: C \rightarrow C$ by $T_{i} x=\frac{\sin x}{i}$ and $S_{i} x=\frac{x^{2}}{x+i}$ for all $x \in C$ and $\frac{1}{(N+1)^{2}} \leq \frac{1}{N^{2}}$.

Suppose that $S^{A}$ is the $S^{A}$-mapping generated by $S_{1}, S_{2}, \ldots, S_{N}, T_{1}, T_{2}, \ldots, T_{N}$, and $\alpha_{1}$, $\alpha_{2}, \ldots, \alpha_{N}$ where $\alpha_{j}=\left(\alpha_{1}^{j}, \alpha_{2}^{j}, \alpha_{3}^{j}\right)$ and $\alpha_{1}^{j}=\alpha_{2}^{j}=\alpha_{3}^{j}=\frac{1}{3}$ for all $j=1,2, \ldots, N$. Define the mapping $G: C \rightarrow C$ by $G x=Q_{C}\left(I-\frac{1}{5} A\right)\left(\frac{1}{2} I+\frac{1}{2} Q_{C}\left(I-\frac{1}{17} B\right)\right) x$ for all $x \in C$. Let the sequence $\left\{x_{n}\right\}$ be generated by (3.1), where $\alpha_{n}=\frac{1}{7 n}, \beta_{n}=\frac{6 n-1}{14 n}$, and $\gamma_{n}=\frac{8 n-1}{14 n}$ for all $n \geq 1$. Then $\left\{x_{n}\right\}$ converges strongly to 0 and $(0,0)$ is a solution of $(1.8)$.

Solution. For every $i=1,2, \ldots, N$, it is easy to see that $T_{i}$ is a nonexpansive mapping and $S_{i}$ is $\frac{1}{i^{2}}$-strictly pseudo-contractive mappings with $\bigcap_{i=1}^{N} F\left(S_{i}\right) \cap \bigcap_{i=1}^{N} F\left(T_{i}\right)=\{0\}$. Then $A$ is $\frac{1}{4}$-inverse strongly accretive and $B$ is $\frac{1}{16}$-inverse strongly accretive. From the definition of $G$, we have $F(G)=\{0\}$ and $(0,0)$ is a solution of (1.8). Then $\mathcal{F}=\bigcap_{i=1}^{N} F\left(S_{i}\right) \cap \bigcap_{i=1}^{N} F\left(T_{i}\right) \cap$ $F(G)=\{0\}$.

For every $n \geq 1$ and $i=1,2, \ldots, N$, the mappings $T_{i}, S_{i}, G, A, B$ and sequences $\left\{\alpha_{n}\right\},\left\{\beta_{n}\right\}$ satisfy all conditions in Theorem 3.1. Since the sequence $\left\{x_{n}\right\}$ is generated by (3.1), from Theorem 3.1, we find that the sequence $\left\{x_{n}\right\}$ converges strongly to 0 and $(0,0)$ is a solution in (1.8).

Next, we will divide our iterations into two cases as follows:

(i) $x_{1}=\frac{\pi}{2}, u=\frac{\pi}{4}$ and $n=N=20$,

(ii) $x_{1}=\frac{\pi}{4}, u=\frac{\pi}{6}$ and $n=N=20$.

Table 1 and Figure 1 show the values of sequence $\left\{x_{n}\right\}$ for both cases.

\section{Conclusion}

(i) Table 1 and Figure 1 show that the sequences $\left\{x_{n}\right\}$ converge to 0 , where $\{0\}=\bigcap_{i=1}^{N} F\left(S_{i}\right) \cap \bigcap_{i=1}^{N} F\left(T_{i}\right) \cap F(G)$.

(ii) Theorem 3.1 guarantees the convergence of $\left\{x_{n}\right\}$ in Example 5.1.

Table 1 The values of $\left\{x_{n}\right\}$ with $x_{1}=\frac{\pi}{2}, u=\frac{\pi}{4}$, and $x_{1}=\frac{\pi}{4}, u=\frac{\pi}{6}$

\begin{tabular}{rll}
\hline $\boldsymbol{n}$ & $\boldsymbol{x}_{\mathbf{1}}=\frac{\pi}{\mathbf{2}}, \boldsymbol{u}=\frac{\pi}{\mathbf{4}}$ & \\
\cline { 2 - 3 } & $\boldsymbol{x}_{\boldsymbol{n}}$ & $\boldsymbol{x}_{\mathbf{1}}=\frac{\pi}{\mathbf{4}}, \boldsymbol{u}=\frac{\pi}{\mathbf{6}}$ \\
\hline 1 & 1.5707963268 & 0.7853981634 \\
2 & 0.6127630899 & 0.3232983687 \\
3 & 0.2701199079 & 0.1495005671 \\
4 & 0.1333284242 & 0.0775756830 \\
5 & 0.0750990544 & 0.0458214332 \\
$\vdots$ & $\vdots$ & $\vdots$ \\
10 & 0.0200438855 & 0.0133281318 \\
$\vdots$ & $\vdots$ & $\vdots$ \\
16 & 0.0114504755 & 0.0076335361 \\
17 & 0.0107016897 & 0.0071344156 \\
18 & 0.0100455821 & 0.0066970377 \\
19 & 0.0094657530 & 0.0063104954 \\
20 & 0.0089495227 & 0.0059663460 \\
\hline
\end{tabular}




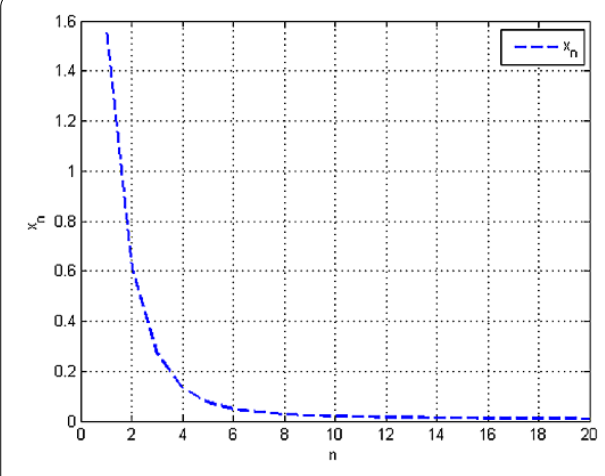

(a) $x_{1}=\frac{\pi}{2}, u=\frac{\pi}{4}$

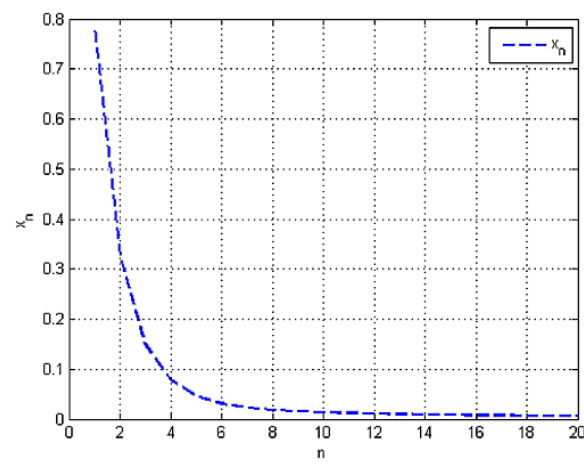

(b) $x_{1}=\frac{\pi}{4}, u=\frac{\pi}{6}$

Figure 1 The convergence of $\left\{x_{n}\right\}$ with different initial values.

(iii) If the sequence $\left\{x_{n}\right\}$ is generated by (4.4), from Theorem 4.4 and Example 5.1, we also see that the sequence $\left\{x_{n}\right\}$ converges to 0 , where $\{0\}=S(C, A) \cap(C, B) \bigcap_{i=1}^{N} F\left(S_{i}\right) \cap \bigcap_{i=1}^{N} F\left(T_{i}\right)$.

\section{Competing interests}

The author declares that they have no competing interests.

\section{Acknowledgements}

This research was supported by the Research Administration Division of King Mongkut's Institute of Technology Ladkrabang.

\section{Received: 2 February 2014 Accepted: 5 May 2014 Published: 19 May 2014}

\section{References}

1. Ansari, QH, Yao, JC: Systems of generalized variational inequalities and their applications. Appl. Anal. 76, 203-217 (2000)

2. Ansari, QH, Schaible, S, Yao, JC: The system of generalized vector equilibrium problems with applications. J. Glob. Optim. 22, 3-16 (2002)

3. Yao, Y, Noor, MA, Noor, KI, Liou, Y-C, Yaqoob, H: Modified extragradient methods for a system of variational inequalities in Banach spaces. Acta Appl. Math. 110, 1211-1224 (2010)

4. Cai, G, Bu, S: Modified extragradient methods for variational inequality problems and fixed point problems for an infinite family of nonexpansive mappings in Banach spaces. J. Glob. Optim. 55, 437-457 (2013)

5. Ceng, LC, Wang, C, Yao, JC: Strong convergence theorems by a relaxed extragradient method for a general system of variational inequalities. Math. Methods Oper. Res. 67, 375-390 (2008)

6. Verma, RU: On a new system of nonlinear variational inequalities and associated iterative algorithms. Math. Sci. Res. Hot-Line 3, 65-68 (1999)

7. Ceng, LC, Schaible, S: Hybrid extragradient-like methods for generalized mixed equilibrium problems, systems of generalized equilibrium problems and optimization problems. J. Glob. Optim. 53(1), 69-96 (2012)

8. Latif, A, Ceng, LC, Ansari, QH: Multi-step hybrid viscosity method for systems of variational inequalities defined over sets of solutions of equilibrium problem and fixed point problems. Fixed Point Theory Appl. 2012, 186 (2012)

9. Ceng, LC, Mezel, SA, Ansari, QH: Implicit and explicit iterative methods for systems of variational inequalities and zeros of accretive operators. Abstr. Appl. Anal., 2013, Article ID 631382 (2013)

10. Ceng, LC, Gupta, H, Ansari, QH: Implicit and explicit algorithms for a system of nonlinear variational inequalities in Banach spaces. J. Nonlinear Convex Anal. (to appear)

11. Cai, G, Bu, S: Strong convergence theorems based on a new modified extragradient method for variational inequality problems and fixed point problems in Banach spaces. Comput. Math. Appl. 62, 2567-2579 (2011)

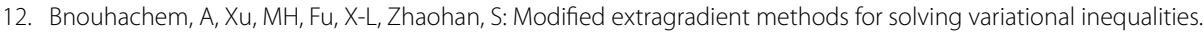
Comput. Math. Appl. 57, 230-239 (2009)

13. Peng, J-W, Yao, J-C: Strong convergence theorems of iterative scheme based on the extragradient method for mixed equilibrium problems and fixed point problems. Math. Comput. Model. 49, 1816-1828 (2009)

14. Aoyama, K, liduka, H, Takahashi, W: Weak convergence of an iterative sequence for accretive operators in Banach spaces. Fixed Point Theory Appl. 2006, Article ID 35390 (2006). doi:10.1155/FPTA/2006/35390

15. Kangtunyakarn, A: A new mapping for finding a common element of the sets of fixed points of two finite families of nonexpansive and strictly pseudo-contractive mappings and two sets of variational inequalities in uniformly convex and $f$-smooth Banach spaces. Fixed Point Theory Appl. 2013, 157 (2013)

16. Xu, HK: An iterative approach to quadratic optimization. J. Optim. Theory Appl. 116, 659-678 (2003)

17. Xu, HK: Inequalities in Banach spaces with applications. Nonlinear Anal. 16, 1127-1138 (1991) 
18. Kitahara, S, Takahashi, W: Image recovery by convex combinations of sunny nonexpansive retraction. Topol. Methods Nonlinear Anal. 2, 333-342 (1993)

19. Reich, S: Asymptotic behavior of contractions in Banach spaces. J. Math. Anal. Appl. 44(1), 57-70 (1973)

20. Cho, YJ, Zhou, HY, Guo, G: Weak and strong convergence theorems for three-step iterations with errors for asymptotically nonexpansive mappings. Comput. Math. Appl. 47, 707-717 (2004)

21. Zhou, $\mathrm{H}$ : Convergence theorems for $\kappa$-strict pseudocontractions in 2-uniformly smooth Banach spaces. Nonlinear Anal. 69, 3160-3173 (2008)

22. Bruck, RE: Properties of fixed point sets of nonexpansive mappings in Banach spaces. Trans. Am. Math. Soc. 179 251-262 (1973)

23. Qin, X, Kang, SM: Convergence theorems on an iterative method for variational inequality problems and fixed point problems. Bull. Malays. Math. Sci. Soc. 33, 155-167 (2010)

10.1186/1687-1812-2014-123

Cite this article as: Kangtunyakarn: The modification of system of variational inequalities for fixed point theory in

Banach spaces. Fixed Point Theory and Applications 2014, 2014:123

\section{Submit your manuscript to a SpringerOpen ${ }^{\circ}$ journal and benefit from:}

- Convenient online submission

- Rigorous peer review

- Immediate publication on acceptance

- Open access: articles freely available online

- High visibility within the field

- Retaining the copyright to your article 